\title{
Museo Universitario de Antropología, MUA
}

\section{Qué es el MUA}

El Museo Universitario de Antropología, MUA, es una institución dedicada a la difusión del pensamiento científico antropológico y del patrimonio cultural salvadoreño, así como a su conservación. Esto se refleja en las colecciones que se presentan en sus salas de exhibición permanentes y la temporal y, además, en las muchas actividades culturales que se realizan según su programación.

\section{Objetivo del MUA}

El Museo Universitario de Antropología tiene como objetivo principal promover un espacio cultural permanente para la adquisición de conocimientos estéticos y valores de conservación, que contribuyan a la formación profesional de la población universitaria y del público en general y su sensibilización ante estos fenómenos, impulsando actividades de promoción de los insumos necesarios para la generación de investigaciones de carácter antropológico e histórico, con el único propósito de desarrollar y difundir la cultura del país.

\section{Qué es lo que hace el MUA}

- Difunde, por medio de exposiciones permanentes y algunas temporales, las diferentes y variadas expresiones tangibles de la cultura salvadoreña.

- Investigar, desarrollar y difundir el acervo antropológico del país de una manera integral, hacia el interior de la comunidad universitaria y del publico en general.

- Genera actividades académicas concretas en la forma de conferencias, seminarios, talleres, presentaciones de libros, ciclos de cine, foros, investigaciones antropológicas y arqueológicas y otros, con el único fin de educar y sensibilizar a la comunidad universitaria y público en general.

- Conserva el patrimonio cultural. 


\section{Salas de exhibición que conforman el MUA}

Para una mejor comprensión, el MUA está distribuido en cinco salas de exhibición permanente, conceptualizadas así:

- Sala que presenta la persistencia del pasado y la etnografía salvadoreña.

- Sala dedicada como tributo al cantaautor nacional don Francisco Antonio Lara Hernández, mejor conocido como Pancho Lara.

- Sala "Instrumentos tradicionales de producción agrícola".

- Sala "Las migraciones".

- Sala de exhibiciones temporales.

- Auditórium de usos múltiples.

\section{Servicio de guías}

Hay cinco estudiantes de antropología que, con previa cita por parte de los interesados en visitar el museo, ofrecen los servicios de guía. El recorrido es de una hora y quince minutos.

\section{Ubicación del museo en la ciudad de San Salvador}

Calle Arce y $17^{\mathrm{a}}$. Av. Norte, $\mathrm{N}^{\mathrm{o}} .1006$, San Salvador, El Salvador, C. A.

Tels. (503) 2275-8836 y (503) 2275-8837

Fax. (503) 2271-4764

E-mail:museo_utec@yahoo.com 


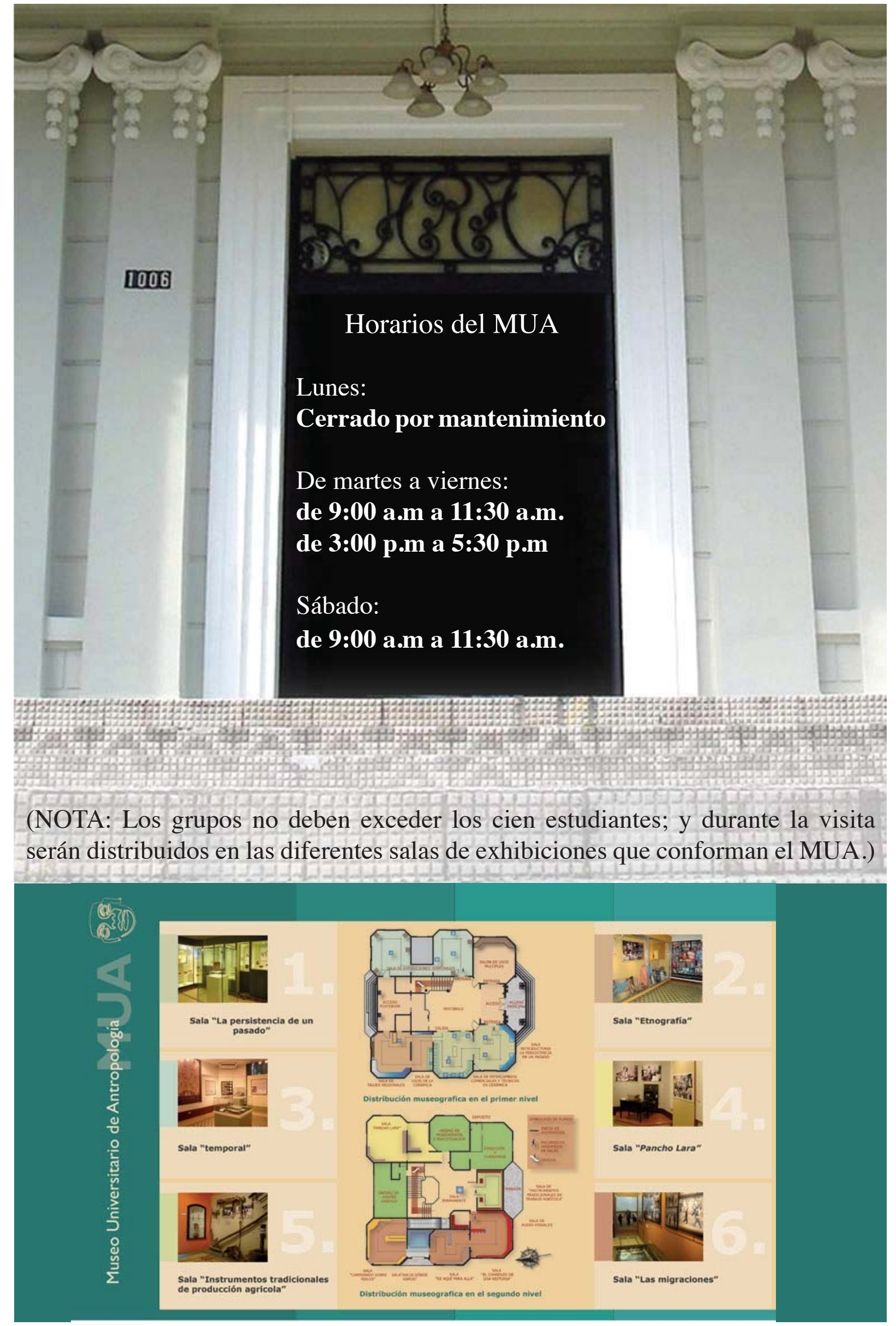




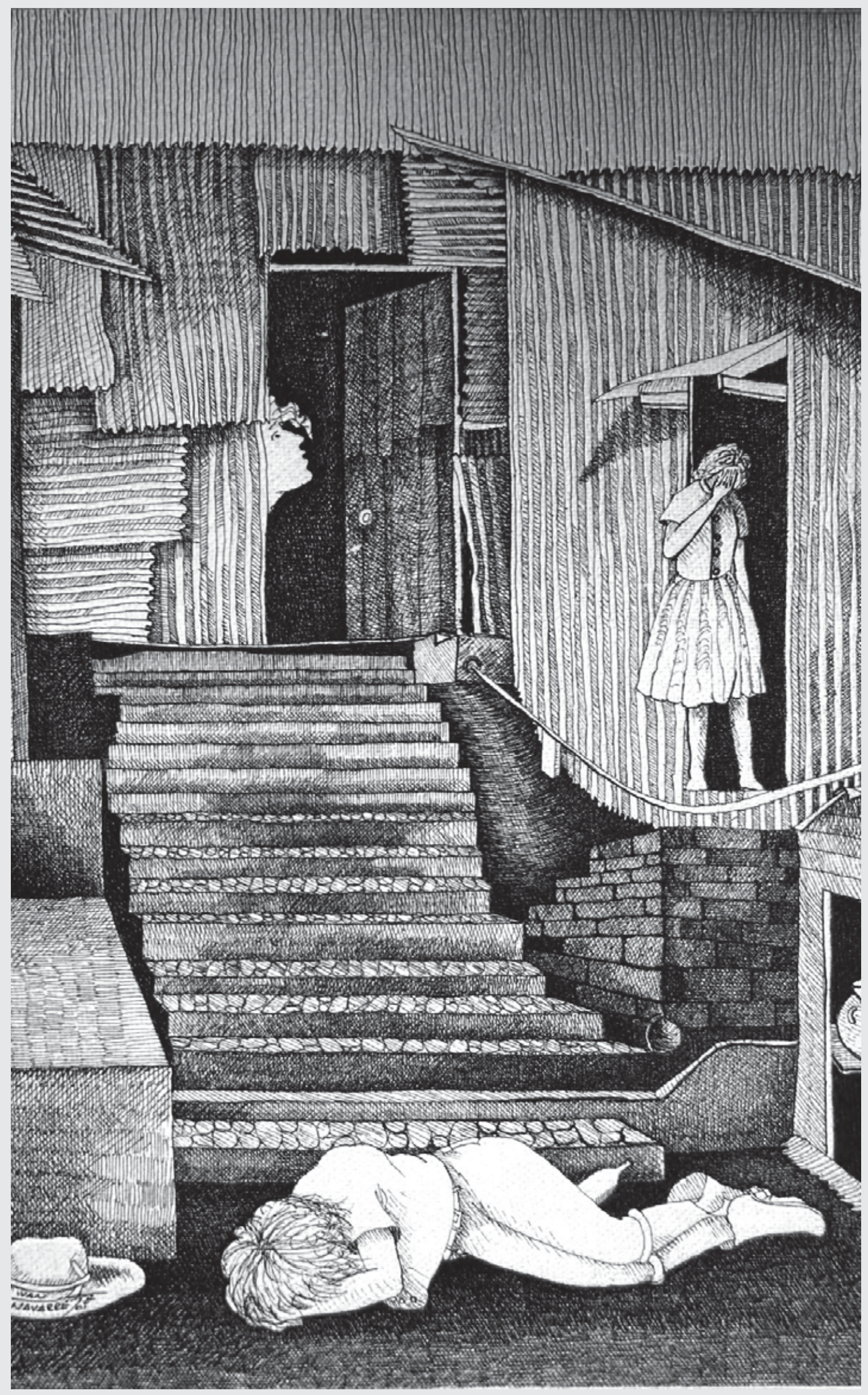

